\title{
Learning by observation in children with autism spectrum disorder
}

\author{
F. Foti ${ }^{1,2 *}$, L. Mazzone ${ }^{3}$, D. Menghini ${ }^{3}$, L. De Peppo ${ }^{3}$, F. Federico ${ }^{4}$, V. Postorino ${ }^{3}$, E. Baumgartner ${ }^{4}$, \\ G. Valeri ${ }^{3}$, L. Petrosini ${ }^{1,2}$ and S. Vicari ${ }^{3}$ \\ ${ }^{1}$ Department of Psychology, Sapienza University of Rome, Italy \\ ${ }^{2}$ IRCCS Fondazione Santa Lucia, Rome, Italy \\ ${ }^{3}$ Child Neuropsychiatry Unit, Department of Neuroscience, Bambino Gesù Children's Hospital, Rome, Italy \\ ${ }^{4}$ Department of Developmental and Social Psychology, Sapienza University of Rome, Italy
}

Background. Observing another person performing a complex action accelerates the observer's acquisition of the same action and limits the time-consuming process of learning by trial and error. Learning by observation requires specific skills such as attending, imitating and understanding contingencies. Individuals with autism spectrum disorder (ASD) exhibit deficits in these skills.

Method. The performance of 20 ASD children was compared with that of a group of typically developing (TD) children matched for chronological age (CA), IQ and gender on tasks of learning of a visuomotor sequence by observation or by trial and error. Acquiring the correct sequence involved three phases: a detection phase (DP), in which participants discovered the correct sequence and learned how to perform the task; an exercise phase (EP), in which they reproduced the sequence until performance was error free; and an automatization phase (AP), in which by repeating the error-free sequence they became accurate and speedy.

Results. In the DP, ASD children were impaired in detecting a sequence by trial and error only when the task was proposed as first, whereas they were as efficient as TD children in detecting a sequence by observation. In the EP, ASD children were as efficient as TD children. In the AP, ASD children were impaired in automatizing the sequence. Although the positive effect of learning by observation was evident, ASD children made a high number of imitative errors, indicating marked tendencies to hyperimitate.

Conclusions. These findings demonstrate the imitative abilities of ASD children although the presence of imitative errors indicates an impairment in the control of imitative behaviours.

Received 26 July 2012; Revised 3 December 2013; Accepted 12 December 2013; First published online 10 January 2014

Key words: Autism spectrum disorder, imitation, observational learning, sequential learning.

\section{Introduction}

In humans and other animals, new competencies may be learned through active experience or observation of others' experiences (Bandura, 1977; Petrosini, 2007; Meltzoff et al. 2009). Observing another person performing a complex action accelerates the observer's acquisition of the same action and limits the timeconsuming process of learning by trial and error (Bird \& Heyes, 2005; Meltzoff et al. 2009). Observational learning not only involves copying an action but also requires that the observer transforms the observation into an action as similar as possible to the model in terms of the goal to be reached and the motor strategies to be applied (Meltzoff \& Andrew,

* Address for correspondence: F. Foti, Ph.D., Department of Psychology, Sapienza University of Rome, Via dei Marsi 78, 00185 Rome, Italy.

(Email: francesca.foti@uniroma1.it)
1995; Gallese \& Goldman, 1998; Meltzoff \& Decety, 2003). It requires the coordination of complex cognitive functions, such as action representation, attention and motivation, and at same time it requires understanding others' gestures, and making inferences about their behaviours (Bandura, 1977; Meltzoff et al. 2009).

Observational learning is already present at birth (Meltzoff \& Moore, 1997; Nadel \& Butterworth, 1998; Nadel, 2002) and it is crucial for developing complex abilities such as language, social responsiveness and the use of instruments to get things done, thus representing a powerful social learning mechanism (Kokkinakki \& Kugiumutzakis, 2000; Meltzoff \& Decety, 2003). Developmental research indicates that the capacity to learn by observation is a slow process in the typical development (Herbert et al. 2006; Esseily et al. 2010). To learn by observation, infants need to attend to and observe the actor, understand others' actions and anticipate the effect of the observed action, and after a delay, match some properties of the 

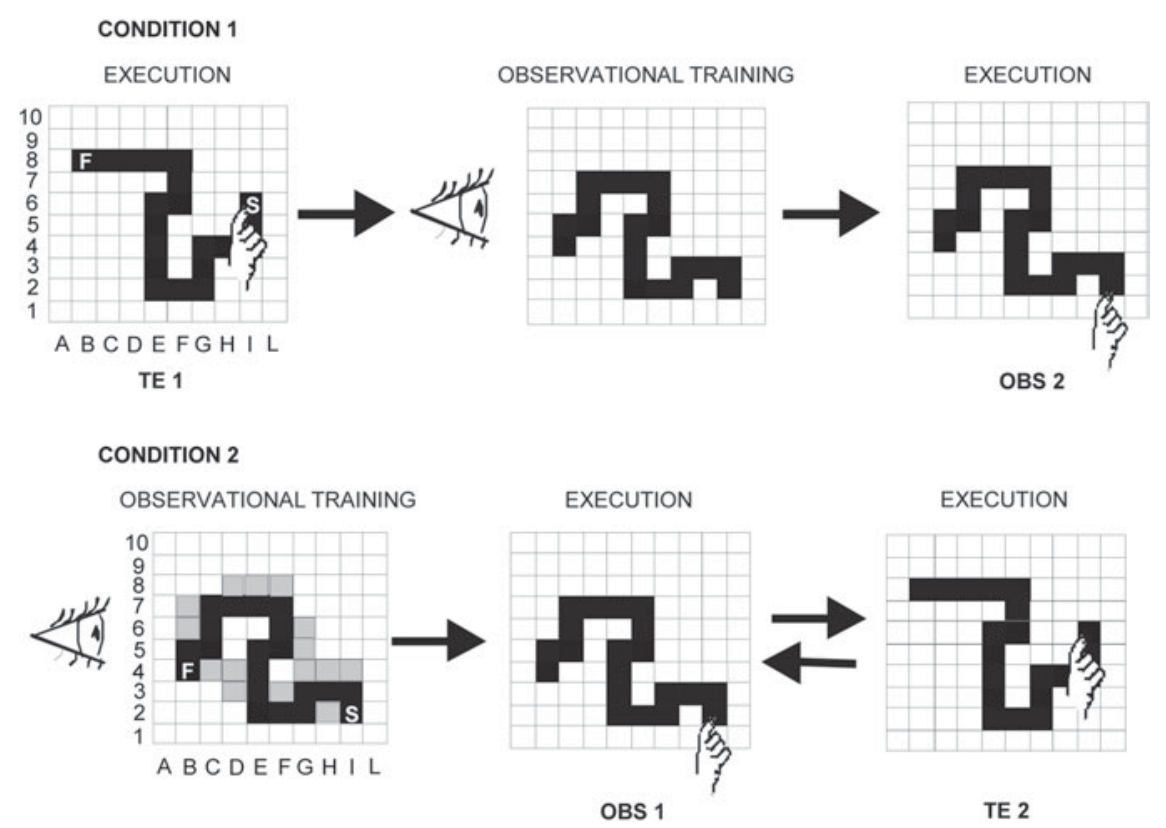

Fig 1. Schematic diagrams of the two experimental conditions. Condition 1 (learning by trial and error followed by observational learning): participants detected a visuomotor sequence by trial and error (TE1), then they observed an actor detecting a sequence different from the one they had previously detected (observational training), and finally they reproduced the observed sequence (OBS2). Condition 2 (observational learning followed by learning by trial and error): participants undertook observational training, then they reproduced the observed sequence (OBS1), and finally they detected by trial and error a different sequence they had not previously observed (TE2). The incorrect positions touched by the actor during the observational training are shown in grey. S, Starting point; F, final point.

observed behaviour. Thus, attending, imitating and understanding contingencies are specific skills required to learn by observation. Research has demonstrated that children with autism spectrum disorder (ASD) display deficits in these skills. Indeed, deficits in attending, such as poor or inconsistent eye contact (APA, 1994), inability to follow eye gaze (Leekam et al. 1998), not orienting to toys or materials (Donnelly et al. 2009) and failure to engage in joint attention (Mundy \& Crowson, 1997), are some of the core diagnostic indicators for autism. In addition, the monitoring of social activities is disrupted early in the developmental progression of autism, limiting the subsequent abilities for observational learning (Shic et al. 2011). As ASD individuals show deficits in crucial skills to learn by observation (Nadel et al. 2011; Taylor \& DeQuinzio, 2012), it is important to clarify the features of observational learning in the presence of ASD. To this aim we chose to use an experimental protocol that allowed observational learning to be analysed, and compared it with learning by trial and error. We have used this protocol previously in studies on children with Williams syndrome and dyslexia (Menghini et al. 2011; Foti et al. 2013), demonstrating that it was suitable for children and faceting multiple components of learning. Performances of a group of ASD children were compared with those of a chronological age (CA)-, gender- and IQ-matched group of typically developing (TD) children by using such a task of learning by observation or by trial and error of a visuomotor sequence (Fig. 1). With the exception of the imitative competencies, both learning tasks required a good knowledge and anticipatory expectations of effects related to actions, goal-directed actions and motor imagery, allowing recombination of novel actions with novel effects.

\section{Method \\ Participants}

The present study encompassed two experimental conditions: learning by trial and error followed by observational learning (Condition 1) and observational learning followed by learning by trial and error (Condition 2) (Fig. 1). Twenty children with ASD (18 males) with a mean CA of 10 years and 5 months (10.05 s.E.M. \pm 0.07 years), and an IQ of $105.85 \pm 2.77$ and 20 TD children matching the ASD participants for CA (10.05 \pm 0.06 years), gender (18 males) and IQ $(108 \pm 2.36)$ were examined in the two conditions. No significant differences in CA and IQ ( $p$ always $>0.1$ ) among participants performing Conditions 1 and 2 were found (Table 1). Cognitive level was measured 
Table 1. Statistical comparisons of chronological age (CA) and IQ between autism spectrum disorder (ASD) groups (ASD1 and ASD2) and typically developing (TD) groups (TD1 and TD2) performing the two experimental conditions

\begin{tabular}{lllllll}
\hline Group & CA (mean \pm S.E.M.) & $F_{1,18}$ & $p$ & IQ (mean \pm S.E.M.) & $F_{1,18}$ & $p$ \\
\hline ASD1 (Condition 1) & $10.08 \pm 0.09$ & 0.18 & 0.67 & $102 \pm 3.43$ & 2.04 & 0.17 \\
ASD2 (Condition 2) & $10.03 \pm 1.08$ & & & $109 \pm 4.15$ & & \\
TD1 (Condition 1) & $10.07 \pm 0.08$ & 0.08 & 0.77 & $107 \pm 3.35$ & 0.17 & 0.68 \\
TD2 (Condition 2) & $10.03 \pm 1.03$ & & & $109 \pm 3.48$ & & \\
\hline
\end{tabular}

by using the Wechsler Intelligence Scale for Children Third Edition (WISC-III; Wechsler, 1991). All participants had normal or corrected-to-normal vision and were screened for exclusion criteria (dyslexia, epilepsy, and any other neurological or psychiatric conditions) prior to taking part.

ASD children were diagnosed according to established criteria (DSM-IV; APA, 1994). The diagnosis was made by a licensed clinician not associated with this research. Module 3 of the Autism Diagnostic Observation Schedule (ADOS; Lord et al. 2005) was used to confirm the diagnosis of autistic spectrum disorder (scores 7-10) or autistic disorder (scores $>10$ ). The mean ADOS total score was of $13.5 \pm 0.85$. Based on the ADOS results, 16 children met the criteria for autistic disorder and four for autistic spectrum disorder. (In the current study, all 20 children are described as ASD.)

The study was approved by the local ethics committee and was conducted according to the Declaration of Helsinki. Parents of the participants gave informed written consent. ASD children were tested in a quiet room at Bambino Gesù Children's Hospital and TD children were tested individually in a quiet room at their schools.

\section{Neuropsychological assessment}

As difficulties in visuomotor integration, deficits of selective or sustained attention and attentional hyperactivity behaviours may interfere with performance on the learning task, ASD children were evaluated for: visuomotor integration, assessed by the BEERY VMI test (VMI; Beery \& Buktenica, 2000); visuospatial attention, evaluated by the Bells Test (BELLS, Italian version; Biancardi \& Stoppa, 1997); and attentional hyperactivity behaviors, estimated by Conners' Parent Rating Scales -Revised: Long Version (CPRS-R:L; Nobile et al. 2007).

\section{Experimental procedure}

Each participant sat in front of a computer touch screen at a distance of $60 \mathrm{~cm}$. In both Conditions 1 and 2, the experimenter acting as the actor (F.F.) sat near the participant. A $10 \times 10$ black matrix appeared on the touch screen. The participant was asked to find a hidden sequence of 'correct' squares prepared in advance by the experimenters. The sequence was composed of 20 adjacent spatial positions in the matrix, which formed a 'snake-like' pattern (Fig. 1). To explain the task to each participant, the experimenter used the same verbal instructions: 'You have to find a snake formed by twenty squares. When you touch a correct square belonging to snake body it will be turned grey and you will hear a sound; conversely, if you touch a wrong square not belonging to the snake, it will be turned red. In this case, you have to find a new grey square. You have to restart each time you find a new correct square. After finding the whole snake, you have to retouch it three times without making lighted red squares'. The participants started touching a grey square, which was the first element of the sequence representing the snake body and was always lit up. In the search for the second correct square, the participants had to touch one of the four squares bordering the grey square by moving in the matrix vertically or horizontally, but never diagonally. Each touched square (correct or wrong) was lit up for $500 \mathrm{~ms}$ and then the light went off again; thus, no trace of the touched sequence remained on the screen.

In learning the sequence by trial and error, the participants tried to find the correct sequence immediately after the verbal instructions. Conversely, in the observational learning task, after the verbal instructions the participants observed the actor while she detected a 20-item sequence by trial and error (observational training). The actor performed the task by always making the same errors in the same positions, so that all participants observed the same pattern of correct and wrong touches. Two minutes after the end of the observational training, the participants were required to reproduce the observed sequence.

A pilot study was conducted to verify that the two sequences arranged to be detected by trial and error (TE) and following observational training (OBS) did not differ as to degree of difficulty. Six TD children (five male) of CA $10.04 \pm 0.05$ years detected the two different sequences by trial and error; the presentation order was randomized among participants. 
Errors (wrong touches) made in detecting each sequence were calculated by a one-way ANOVA with repeated measures. The analysis failed to reveal any significant difference between sequences $\left(F_{1,5}=0.094\right.$, $p=0.77$ ), confirming that they were of the same difficulty.

\section{Condition 1: learning by trial and error followed by observational learning}

Ten (all male) ASD and 10 (all male) TD children (Table 1) first detected a sequence by trial and error (TE1) and, $10 \mathrm{~min}$ after the end of the task, they were submitted to the observational training. After $2 \mathrm{~min}$, participants were required to reproduce the observed sequence (OBS2). There was no fixed time limit for executing the task.

\section{Condition 2: learning by observation followed by learning by trial and error}

Ten (eight male) ASD and 10 (eight male) TD children (Table 1) first observed the actor detect a sequence (OBS1) and then reproduce it. After $10 \mathrm{~min}$, they had to detect a different sequence by trial and error (TE2). Thus, the difference between the two conditions was that participants reproduced a sequence learned by observation after (Condition 1) or before (Condition 2) the detection of a different sequence by trial and error (Fig. 1).

\section{Mental representative mapping abilities}

At the end of the reproduction of each sequence, participants were asked to draw the arrangement of the sequence on a $10 \times 10$ matrix sketched on a sheet of paper. Thus, each participant drew the arrangement of the two sequences, one learned by observation and the other by trial and error. Mapping abilities were evaluated by tabulating the variable 'error' into three categories: 'no error', 'one error' and 'more than one error'.

\section{Parameters}

Regardless of whether learning took place observationally or by trial and error, the two tasks involved three phases: the detection phase (DP), which ended once the participants found the 20th correct position; the exercise phase (EP), in which they had to repeat the 20-item sequence until their performance was error free; and the automatization phase (AP), which ended when the correct sequence was repeated three consecutive times without errors.

The parameters measured were: DP errors, that is the number of incorrect squares touched in detecting the sequence; EP repetitions, the number of replications needed to achieve an error-free performance; and AP times (in ms), the time spent carrying out the three correct repetitions of the sequence. Considering DP and EP together, we calculated perseverations, consecutive errors touching the same square or a fixed sequence of squares; sequence errors, touching a correct square at the 'wrong' moment (i.e. touching E4 before E3; Fig. 1); side-by-side errors, errors in the squares bordering the correct sequence (i.e. D5; Fig. 1); illogical errors, errors in any other square (i.e. C10; Fig. 1); and, exclusively in the observational learning task, imitative errors, errors in the wrong squares unnecessarily touched by the actor during the observational training (i.e. G4; Fig. 1).

\section{Statistical analyses}

The data were first tested for normality (using the Shapiro-Wilk test) and homoscedasticity (the Levene test) and then compared by using two-, threeor four-way analyses of variance (ANOVAs) followed by post-hoc multiple comparisons using the NewmanKeuls test. The two-way ANOVAs were performed by applying the mixed model for independent variable (group) and repeated measures (square). Three-way ANOVAs (group $\times$ condition $\times$ task) were performed on most parameters, and the four-way ANOVA was performed on AP times by applying the mixed model for independent variables (group, condition and task) and repeated measures (times or error). Correlations between data were tested by means of Pearson's $r$. Error categories of mapping abilities were analysed by $\chi^{2}$. Statistical analyses were performed by using Statistica 8.0 for Windows and the significance level was set at $p<0.05$.

\section{Results}

\section{Learning tasks}

In comparison with TD children, ASD participants performed a number of DP errors not significantly different after the observational trainings (OBS1OBS2 tasks) and significantly higher in TE1 (Fig. 2a), as revealed by post-hoc comparisons on the second-order interaction of the three-way ANOVA (group $\times$ condition $\times$ task) $\left(F_{1,36}=8.07, p=0.0073\right)$.

In the EP, ASD participants needed a similar number of repetitions to reach error-free performances in comparison to TD regardless of condition (1 or 2 ) and task (OBS or TE), as revealed by the lack of a significant group effect of the three-way ANOVA (group $\times$ condition $\times$ task) $\left(F_{1,36}=1.33, p=0.25\right)$ (Fig. $\left.2 b\right)$.

Furthermore, ASD children performed a number of perseverations significantly higher than TD, as revealed by the significant group effect of the three-way 
(a)

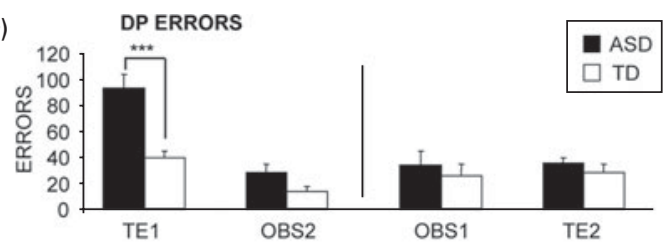

(b)

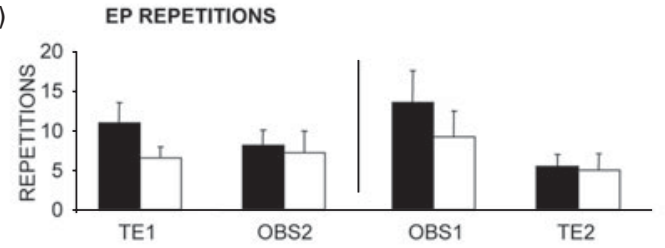

(c)
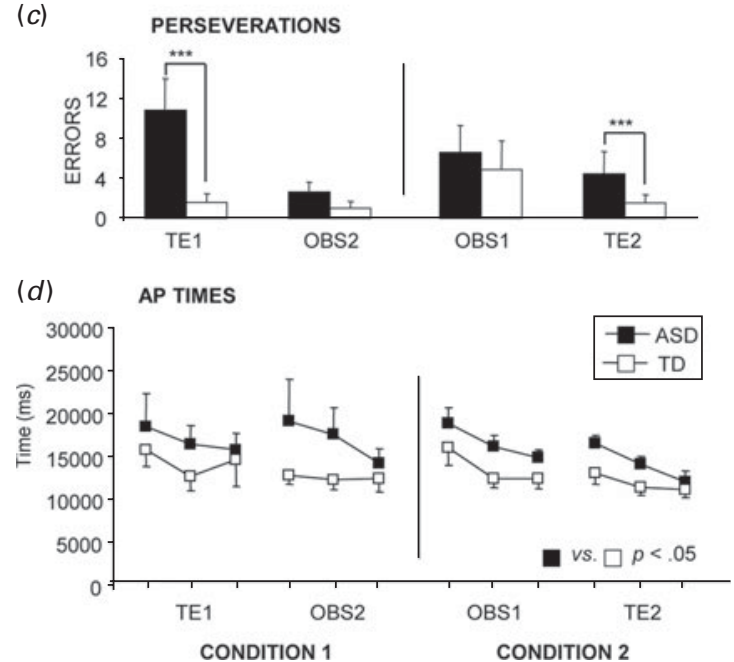

Fig 2. Performances of autism spectrum disorder (ASD) and typically developing (TD) children. Data are expressed as mean \pm S.E.M. The asterisks indicate the significance level of post-hoc comparisons between groups: ${ }^{* *} p<0.0005$. DP, Detection phase; EP, exercise phase; AP, automatization phase. See Fig. 1 for explanation of TE1, TE2, OBS1 and OBS2.

ANOVA (group $\times$ condition $\times$ task) $\left(F_{1,36}=4.53, p=0.04\right)$ (Fig. 2c). Post-hoc comparisons on the first-order interaction group $\times$ task $\left(F_{1,36}=5.83, p=0.02\right)$ revealed that the groups differed significantly only in the TE tasks $(p=0.00036)$, given the higher number of perseverations displayed by ASD participants.

A four-way ANOVA (group $\times$ condition $\times$ task $\times$ time) on AP times revealed that, although all participants exhibited significantly reduced times as the task continued (time effect: $F_{2,72}=9.99, p=0.00014$ ), ASD children were significantly slower than TD (group effect: $\left.F_{1,36}=4.58, p=0.039\right)$, revealing their difficulty in automatizing the sequences (Fig. $2 d$ ).

\section{Analysis of error}

A four-way ANOVA (group $\times$ condition $\times$ task $\times$ error) revealed a significant group effect $\left(F_{1,36}=7.43\right.$, $p=0.009$ ). Post-hoc comparisons on the significant third-order interaction $\left(F_{3,108}=3.07, p=0.03\right)$ revealed that ASD children differed significantly from TD participants, performing more imitative errors in OBS1 $(p=0.017)$, along with sequence $(p=0.0011)$ and side-by-side ( $p=0.0001)$ errors in TE1 (Fig. 3).

As for side-by-side errors, the high number of errors made by ASD children was due to their significantly more frequent wrong touching when a change of direction was required (squares I3, F4, F3, E7) (Fig. 4), as revealed by post-hoc comparisons made on the significant interaction $\left(F_{41,738}=2.39, p<0.00001\right)$ of the twoway ANOVA (group $\times$ square).

\section{Mapping abilities}

No significant difference between groups and among error categories was found in any sequence (always $p>0.3$ ), an index of similar mental representative mapping abilities in both groups.

\section{Neuropsychological findings}

The scores of each ASD participant on the VMI, BELLS and CPRS-R:L tasks were transformed into standard scores based on normative data. All ASD children showed scores that fell within a maximum of 1.5 standard deviations below the average (VMI standard scores: 101.9 \pm 3.6 ; BELLS selective attention $z$ score: $-0.8 \pm 0.3$; BELLS sustained attention $z$ score: $-1.3 \pm 0.4$; CPRS-R:L DSM-IV total $t$ score: $60.6 \pm 3.1$ ). Moreover, in ASD participants, no significant correlation between learning performances and VMI, BELLS and CPRS-R:L was found (Table 2).

\section{Discussion}

ASD participants were severely impaired in detecting a visuomotor sequence by trial and error when the task was first proposed as in TE1, whereas they were as efficient as TD children in reproducing the previously observed sequence as in OBS1. Notably, in the DP the positive effect of observational training was evident not only in reproducing the previously observed sequences as in OBS1 and OBS2 but also in subsequently detecting a sequence by trial and error as in TE2. However, it should be considered that a practice effect, inescapably present in any second task, might have improved performances in both groups (Fig. 2a). Thus, through the observational training, a kind of visuomotor priming, ASD participants learned to put into action the correct decision-making strategy and the appropriate strategies to discover rules and generate new knowledge to be automated. The high number of errors in the DP in TE1 of ASD participants may reflect a deficit in the executive function. 

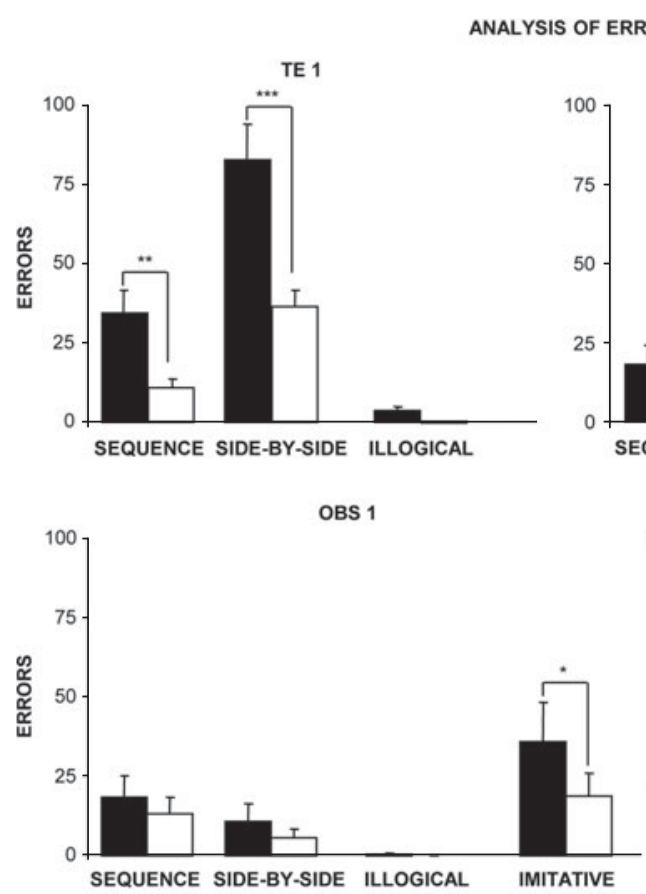

OBS 2

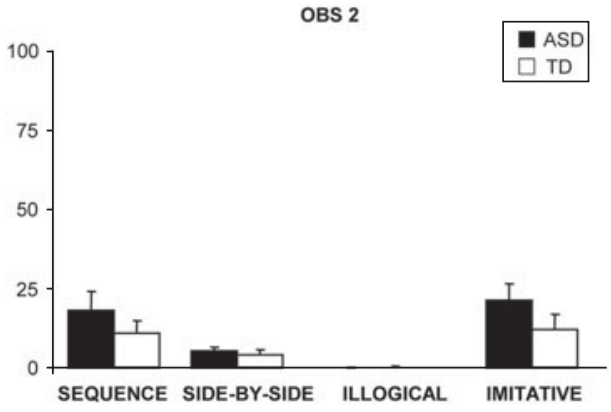

TE 2

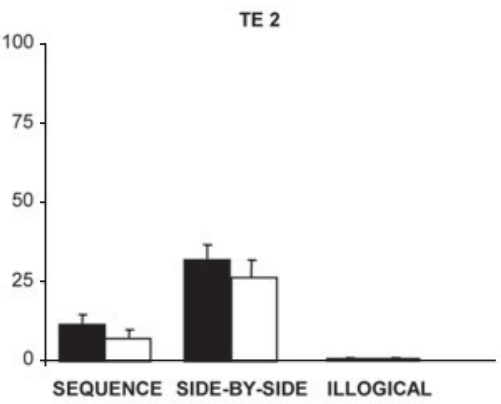

ERRORS

Fig 3. Errors of autism spectrum disorder (ASD) and typically developing (TD) children. Data are expressed as mean \pm S.E.M. The asterisks indicate the significance level of post-hoc comparisons between groups: ${ }^{*} p<0.05,{ }^{* *} p<0.005,{ }^{* * *} p<0.0005$. See Fig. 1 for explanation of TE1, TE2, OBS1 and OBS2.

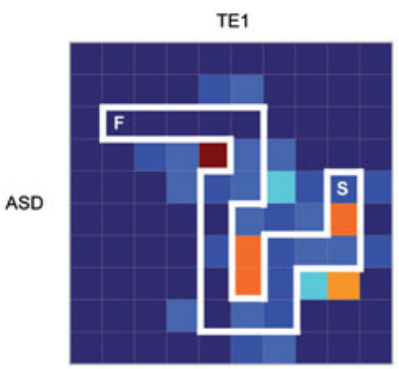

TE1

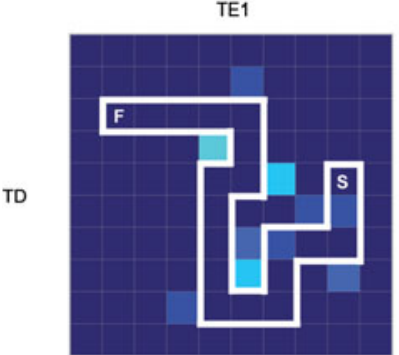

CONDITION

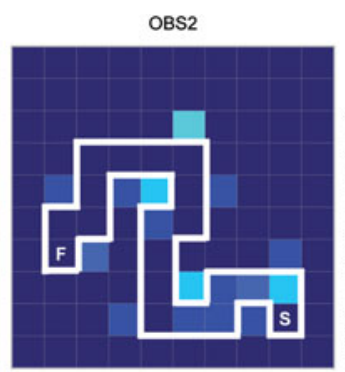

OBS2

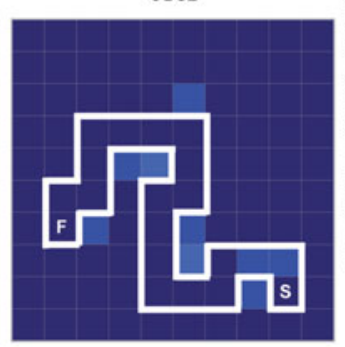

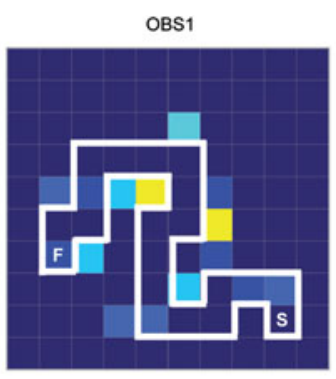
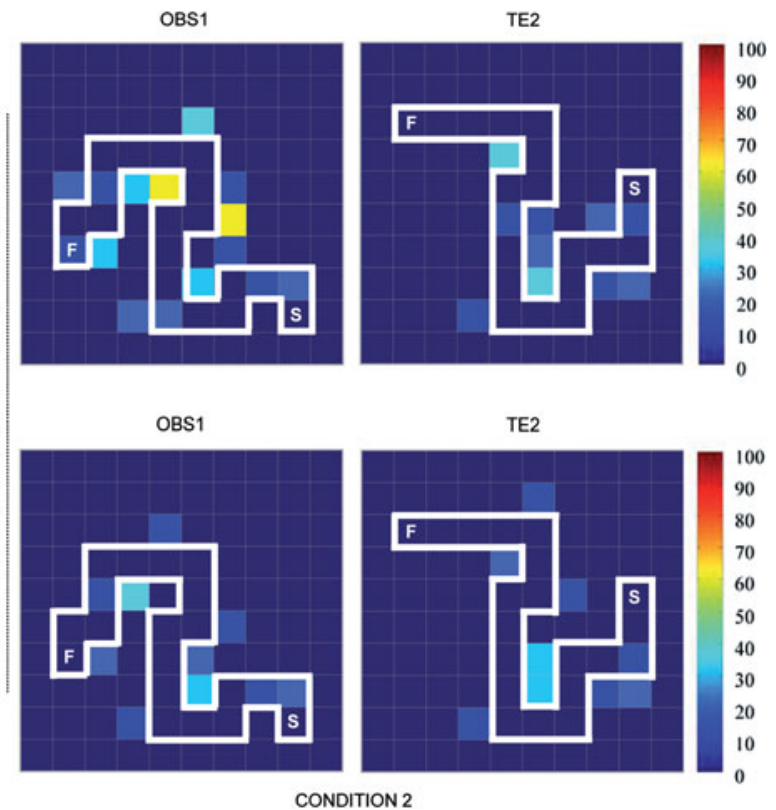

Fig 4. Incorrect squares touched on the screen by autism spectrum disorder (ASD) and typically developing (TD) children in performing the tasks. On the right, the chromatic scale indicates the sum of incorrectly touched squares (brown and blue denote maximal and minimal values respectively). S, starting point; F, final point. See Fig. 1 for explanation of TE1, TE2, OBS1 and OBS2.

'Executive function' is traditionally used as an umbrella term for functions such as planning, working memory, impulse control, inhibition, set-shifting and monitoring of action (Stuss \& Knight, 2002). Deficits such as planning (Robinson et al. 2009), flexibility (Corbett et al. 2009) and response inhibition 


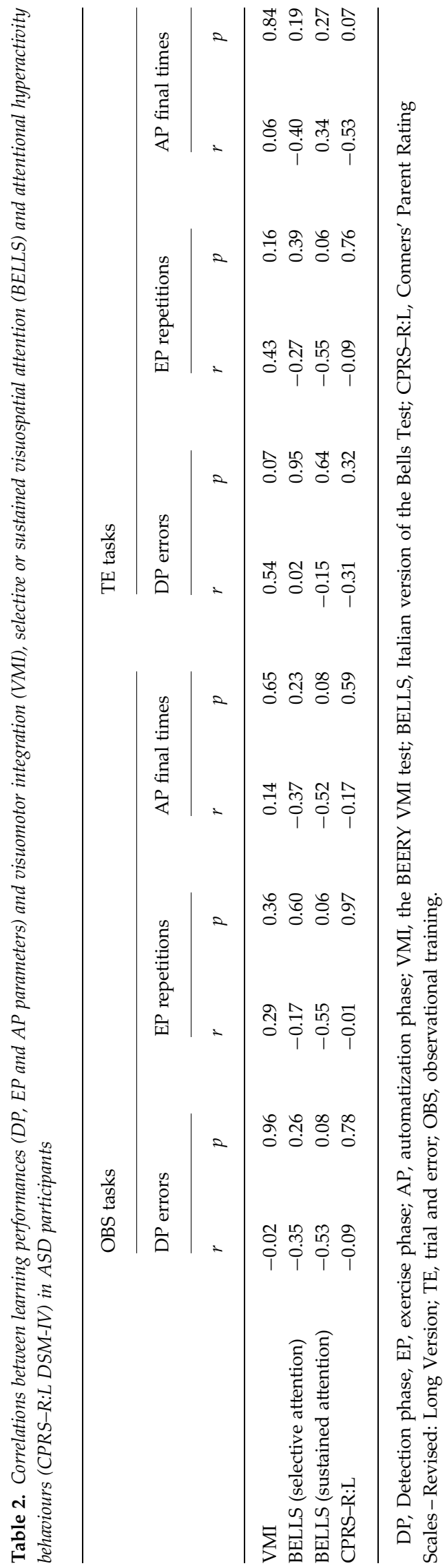

(Agam et al. 2010), along with initiating, sequencing and monitoring the task (Hill, 2004; Robinson et al. 2009), described repeatedly in autism, could influence the capacities of ASD children to perform efficiently in the DP.

In the EP, ASD children were as efficient as TD participants (Fig. 2b). As the EP mainly requires working memory, memory load to form and maintain the trace of correct sequences, long-term memory and attentional demands to monitor its correct execution, the efficient EP performance of ASD participants could indicate the sparing of these specific abilities. In fact, the ASD high-level ability to arrange simple visual elements (Shah \& Frith, 1993; Mottron et al. 1999; O'Riordan et al. 2001) represents an advantage in performing the EP that involves the encoding and retrieval of visuospatial components. Their efficient EP performance is also in agreement with some studies indicating that ASD children are not impaired in spatial working memory tasks or in search tasks (Klin et al. 1999; Ozonoff \& Strayer, 2001). Thus, the autism cognitive style favouring the use of visuospatial coding strategies seems to allow for efficient performance in the $\mathrm{EP}$, which requires mnesic and attentional visuospatial abilities more than problem-solving and planning capacities as in the DP. The efficient EP performance may reflect a way of thinking made up of series of images, instead of words (Grandin, 1995, 2009; Kunda \& Goel, 2011). In addition, the efficient mapping abilities requiring visual imagery found in ASD children in the present research tend in this direction. The relative strength in mental rotation and visual imagery functions described in ASD children supports this proposal (Falter et al. 2008; Soulières et al. 2011).

In the AP, ASD children displayed longer automatization times than TD participants, although these times diminished progressively as repetitions continued (Fig. 2d). This suggests a partial deficit in automatization processes linked to the functions of subcortical structures, such as the cerebellum and basal ganglia, and to their bidirectional interconnections with parietal and frontal cortices (Seidler et al. 2005; Menghini et al. 2006; Torriero et al. 2011). Indeed, neuroimaging and autoptic data on ASD individuals have consistently described increased volumes of the caudate nucleus (Sears et al. 1999; Luna et al. 2002; Hollander et al. 2005; Haznedar et al. 2006; Rojas et al. 2006; Langen et al. 2009; Neuhaus et al. 2010) in addition to reduced volumes of cerebellar vermis and hemispheres (Bailey et al. 1998; Verhoeven et al. 2010). Moreover, in ASD individuals an altered cerebellar activation has been reported during simple motor tasks (Allen et al. 2004; Martineau et al. 2010). Even the types of errors made by ASD children in the present research support the 'subcortical' 
involvement. In both trial-and-error tasks, but not in both observational learning tasks, ASD participants made more perseverative errors than TD children, once more suggesting a deficit in top-down executive control (Fig. 2c). Perseverations may be symptoms not only of prefrontal dysfunction but also of cerebellar and basal ganglia damage provoking 'frontal-like' cognitive deficits (Middleton \& Strick, 2000; Seidler et al. 2005; Clarke et al. 2008; Ersche et al. 2011). In effect, the described association of caudate volume with repetitive behaviours emphasizes the striatal role in repetitive behaviours characterizing ASD (Hollander et al. 2005; Langen et al. 2009). Functional neuroimaging findings in ASD individuals evidenced a disruption in frontostriatal and frontoparietal functional connectivity (Silk et al. 2006; Just et al. 2007). Moreover, ASD repetitive behaviours correlate with white matter indices in posterior brain pathways, including the cerebellum (Cheung et al. 2009). Data from mouse models have also indicated that cerebellar pathology may play a causal role in generating repetitive behaviours (Martin et al. 2010; Tsai et al. 2012).

As for the remaining errors, all participants made an analogously low number of illogical errors, indicating that all participants similarly managed task fundamentals (Figs 3 and 4). Furthermore, ASD children made more sequence errors and side-by-side errors than TD participants in TE1, particularly when a change of direction was required. Errors in stopping the easier 'keep-straight' response and performing the more demanding 'turn-left' response resulted in suppressing a previously correct but then inappropriate response. Not by change, correctly responding requires processes, such as response inhibition, cognitive flexibility and attentional shifting (Chambers et al. 2007; Swick et al. 2011), already indicated as being impaired in ASD participants (Pellicano, 2012). Of note, despite the positive effect of the observational training, in OBS1 ASD participants made a high number of imitative errors, indicating their tendency to hyperimitate (Fig. 3). Such an increase in imitation and a reduction in imitation inhibition fit with the ASD symptoms of echolalia and echopraxia (Rutter, 1974; Russell, 1997; Spengler et al. 2010), although a recent report has criticized the notion of an ASD tendency to overimitate (Marsh et al. 2013).

A tempting interpretation of the present results supports the broken mirror neuron system hypothesis in ASD (Ramachandran \& Oberman, 2006). The mirror system provides the observer with a matching motor representation in one's own motor system (Iacoboni et al. 1999; Buccino et al. 2001). Action mirroring is assumed to underlie imitation of observed actions and social understanding (Rizzolatti \& Craighero, 2004). It has been suggested that, along with emotion sharing and theory of mind, a deficit in perception-action matching is a primary difficulty in ASD (Rogers \& Pennington, 1991) and that early mirror system dysfunction might lead to a cascade of developmental impairments (Williams et al. 2001, 2004). Furthermore, weaker responses in mirror system regions in ASD individuals during movement observation, execution and imitation have been described (Théoret et al. 2005; Dapretto et al. 2006; Bernier et al. 2007). However, more recent studies do not support the view of a global failure in the mirror system in autism (Leighton et al. 2008; Southgate \& Hamilton, 2008). Thus, rather than the mirror system being 'broken', it may be that control over its output or top-down modulation of this system are atypical (Hamilton et al. 2007; Hamilton, 2008; et al. 2010; Kana et al. 2011; Cook et al. 2012, 2013). The present results are consistent with this latter hypothesis. Indeed, we evidenced the beneficial effect of the observational training in ASD children so that their ability to reproduce a previously observed visuomotor pattern was almost completely spared. Nevertheless, the large number of imitative errors seems to indicate an impaired function of imitation inhibition, advancing problems in the control of imitative behaviours rather than in imitation per se (Shih et al. 2010).

In conclusion, elucidating the disturbances to the multiple learning and memory systems in autism could have several potential implications for both research and clinical practice. A clear understanding of the learning and memory deficits in ASD could target therapies to remediation of the specific deficits. Understanding the cognitive profile with its relative strengths and weaknesses may ultimately help in developing optimal therapeutic interventions tailored to each individual to facilitate the acquisition of new abilities and competencies. Furthermore, it may allow the best teaching approach along with social integration and development of self-efficacy and selfconfidence. Thus, the present results can promote progress in three main areas: early intervention programmes, learning outside of school and formal education. Children are born learning, and how much they learn depends on environmental input. The recognition that the right input at the right time has cascading effects can lead to early interventions in children at risk, as ASD children may be. Indeed, programmes enhancing early social interactions and contingencies can produce significant long-term improvements in academic achievement and social adjustment.

\section{Acknowledgements}

We thank the children with ASD and their parents for making this study possible. 


\section{Declaration of Interest}

None.

\section{References}

Agam Y, Joseph RM, Barton JJ, Manoach DS (2010). Reduced cognitive control of response inhibition by the anterior cingulate cortex in autism spectrum disorders. NeuroImage 52, 336-347.

Allen G, Muller RA, Courchesne E (2004). Cerebellar function in autism: functional magnetic resonance image activation during a simple motor task. Biological Psychiatry 56, 269-278.

APA (1994). Diagnostic and Statistical Manual of Mental Disorders, 4th edn. American Psychiatric Association: Washington, DC.

Bailey A, Luthert P, Dean A, Harding B, Janota I, Montgomery M, Rutter M, Lantos P (1998).

A clinicopathological study of autism. Brain 121, 889-905.

Bandura A (1977). Social Learning Theory. Prentice Hall: Englewood Cliffs, NJ.

Beery KE, Buktenica NA (2000). The Beery-Buktenica Developmental Test of Visual-Motor Integration with Additional Tests of Visual Perception and Motor Coordination [Italian translation by C. Preda]. O.S. Organizzazioni Speciali: Florence.

Bernier R, Dawson G, Webb S, Murias M (2007). EEG mu rhythm and imitation impairments in individuals with autism spectrum disorder. Brain and Cognition 64, 228-237.

Biancardi A, Stoppa E (1997). The modified Bells Test: a proposal for the study of attention in childhood [in Italian]. Psichiatria dell'Infanzia e dell'Adolescenza 64, 73-84.

Bird G, Heyes C (2005). Effector-dependent learning by observation of a finger movement sequence. Journal of Experimental Psychology: Human Perception and Performance 31, 262-275.

Buccino G, Binkofski F, Fink GR, Fadiga L, Fogassi L, Gallese V, Seitz RJ, Zilles K, Rizzolatti G, Freund HJ (2001). Action observation activates premotor and parietal areas in a somatotopic manner: an fMRI study. European Journal of Neuroscience 13, 400-404.

Chambers CD, Bellgrove MA, Gould IC, English T, Garavan H, McNaught E, Kamke M, Mattingley JB (2007). Dissociable mechanisms of cognitive control in prefrontal and premotor cortex. Journal of Neurophysiology 98, 3638-3647.

Cheung C, Chua SE, Cheung V, Khong PL, Tai KS, Wong TK, Ho TP, McAlonan GM (2009). White matter fractional anisotrophy differences and correlates of diagnostic symptoms in autism. Journal of Child Psychology and Psychiatry 50, 1102-1112.

Clarke HF, Robbins TW, Roberts AC (2008). Lesions of the medial striatum in monkeys produce perseverative impairments during reversal learning similar to those produced by lesions of the orbitofrontal cortex. Journal of Neuroscience 28, 10972-10982.

Cook J, Barbalat G, Blakemore SJ (2012). Top-down modulation of the perception of other people in schizophrenia and autism. Frontiers in Human Neuroscience 6, 175 .

Cook J, Swapp D, Pan X, Bianchi-Berthouze N, Blakemore SJ (2013). Atypical interference effect of action observation in autism spectrum conditions. Psychological Medicine. Published online: 13 June 2013. doi:10.1017/S0033291713001335.

Corbett BA, Constantine LJ, Hendren R, Rocke D, Ozonoff S (2009). Examining executive functioning in children with autism spectrum disorder, attention deficit hyperactivity disorder and typical development. Psychiatry Research 166, 210-222.

Dapretto M, Davies MS, Pfeifer JH, Scott AA, Sigman M, Bookheimer SY, Iacoboni M (2006). Understanding emotions in others: mirror neuron dysfunction in children with autism spectrum disorders. Nature Neuroscience 9, 28-30.

Donnelly JI, Luyben PD, Zan CS (2009). Increasing eye contact toward learning materials in a toddler with autism. Journal of Prevention and Intervention in the Community 37, 170-176.

Ersche KD, Roiser JP, Abbott S, Craig KJ, Muller U, Suckling J, Ooi C, Shabbir SS, Clark L, Sahakian BJ, Fineberg NA, Merlo-Pich EV, Robbins TW, Bullmore ET (2011). Response perseveration in stimulant dependence is associated with striatal dysfunction and can be ameliorated by a $\mathrm{D}(2 / 3)$ receptor agonist. Biological Psychiatry 70, 754-762.

Esseily R, Nadel J, Fagard J (2010). Object retrieval through observational learning in 8- to 18-month-old infants. Infant Behavior and Development 33, 695-699.

Falter CM, Plaisted KC, Davis G (2008). Visuo-spatial processing in autism - testing the predictions of extreme male brain theory. Journal of Autism and Developmental Disorder 38, 507-515.

Foti F, Menghini D, Mandolesi L, Federico F, Vicari S, Petrosini L (2013). Learning by observation: insights from Williams syndrome. PLoS One 8, e53782.

Gallese V, Goldman A (1998). Mirror neurons and the simulation theory of mind-reading. Trends in Cognitive Sciences 2, 493-501.

Grandin T (1995). Thinking in Pictures. Vintage Press Random House: New York.

Grandin T (2009). How does visual thinking work in the mind of a person with autism? Philosophical Transactions of the Royal Society of London. Series B, Biological Sciences 364, 1437-1442.

Hamilton AF (2008). Emulation and mimicry for social interaction: a theoretical approach to imitation in autism. Quarterly Journal of Experimental Psychology 61, 101-115.

Hamilton AF, Brindley RM, Frith U (2007). Imitation and action understanding in autistic spectrum disorders: how valid is the hypothesis of a deficit in the mirror neuron system? Neuropsychologia 45, 1859-1868.

Haznedar MM, Buchsbaum MS, Hazlett EA, LiCalzi EM, Cartwright C, Hollander E (2006). Volumetric analysis and three-dimensional glucose metabolic mapping of the striatum and thalamus in patients with autism spectrum disorders. American Journal of Psychiatry 163, 1252-1263. 
Herbert J, Gross J, Hayne H (2006). Age-related changes in deferred imitation between 6 and 9 months of age. Infant Behaviour and Development 29, 136-139.

Hill EL (2004). Executive dysfunction in autism. Trends in Cognitive Sciences 8, 26-32.

Hollander E, Anagnostou E, Chaplin W, Esposito K, Haznedar MM, Licalzi E, Wasserman S, Soorya L, Buchsbaum M (2005). Striatal volume on magnetic resonance imaging and repetitive behaviors in autism. Biological Psychiatry 58, 226-232.

Iacoboni M, Woods RP, Brass M, Bekkering H, Mazziotta JC, Rizzolatti G (1999). Cortical mechanisms of human imitation. Science 286, 2526-2528.

Just MA, Cherkassky VL, Keller TA, Kana RK, Minshew NJ (2007). Functional and anatomical cortical underconnectivity in autism: evidence from an FMRI study of an executive function task and corpus callosum morphometry. Cerebral Cortex 17, 951-961.

Kana R, Wadsworth H, Travers B (2011). A systems level analysis of the mirror neuron hypothesis and imitation impairments in autism spectrum disorders. Neuroscience and Biobehavioral Reviews 35, 894-902.

Klin AK, Sparrow SS, de Bildt A, Cicchetti DV, Cohen DJ, Volkmar FR (1999). A normed study of face recognition in autism and related disorders. Journal of Autism and Developmental Disorders 29, 499-508.

Kokkinakki T, Kugiumutzakis G (2000). Basic aspects of vocal imitation in infant-parent interaction during the first 6 months. Journal of Reproductive and Infant Psychology 18, 173-187.

Kunda M, Goel AK (2011). Thinking in Pictures as a cognitive account of autism. Journal of Autism and Developmental Disorders 41, 1157-1177.

Langen M, Schnack HG, Nederveen H, Bos D, Lahuis BE, de Jonge MV, van Engeland H, Durston S (2009). Changes in the developmental trajectories of striatum in autism. Biological Psychiatry 66, 327-333.

Leekam SR, Hunnisett E, Moore C (1998). Targets and cues: gaze-following in children with autism. Journal of Child Psychology and Psychiatry 39, 951-962.

Leighton J, Bird G, Charman T, Heyes C (2008). Weak imitative performance is not due to a functional 'mirroring' deficit in adults with autism spectrum disorders. Neuropsychologia 46, 1041-1049.

Lord C, Rutter M, Di Lovore PC, Risi S (2005). Autism Diagnostic Observation Schedule. Organizzazioni Speciali: Florence, Italy.

Luna B, Minshew NJ, Garver KE, Lazar NA, Thulborn KR, Eddy WF, Sweeney JA (2002). Neocortical system abnormalities in autism: an fMRI study of spatial working memory. Neurology 59, 834-840.

Marsh L, Pearson A, Ropar D, Hamilton A (2013). Children with autism do not overimitate. Current Biology 23, R266-R268.

Martin LA, Goldowitz D, Mittleman G (2010). Repetitive behavior and increased activity in mice with Purkinje cell loss: a model for understanding the role of cerebellar pathology in autism. European Journal of Neuroscience 31, 544-555.
Martineau J, Andersson F, Barthelemy C, Cottier JP, Destrieux C (2010). Atypical activation of the mirror neuron system during perception of hand motion in autism. Brain Research 1320, 168-175.

Meltzoff AN, Andrew N (1995). Understanding the intentions of others: re-enactment of intended acts by 18-month-old children. Developmental Psychology 31, 838-850.

Meltzoff AN, Moore MK (1997). Imitation of facial and manual gestures by human neonates. Science 198, 75-78.

Meltzoff AN, Decety J (2003). What imitation tells us about social cognition: a rapprochement between developmental psychology and cognitive neuroscience. Philosophical Transactions of the Royal Society of London. Series B, Biological Sciences 358, 491-500.

Meltzoff AN, Kuhl PK, Movellan J, Sejnowski TJ (2009). Foundations for a new science of learning. Science 325, 284-288.

Menghini D, Hagberg GE, Caltagirone C, Petrosini L, Vicari $S$ (2006). Implicit learning deficits in dyslexic adults: an fMRI study. NeuroImage 33, 1218-1226.

Menghini D, Vicari S, Mandolesi L, Petrosini L (2011). Is learning by observation impaired in children with dyslexia? Neuropsychologia 49, 1996-2003.

Middleton FA, Strick PL (2000). Basal ganglia and cerebellar loops: motor and cognitive circuits. Brain Research. Brain Research Reviews 31, 236-250.

Mottron L, Belleville S, Ménard E (1999). Local bias in autistic subjects as evidenced by graphic tasks: perceptual hierarchization or working memory deficit? Journal of Child Psychology and Psychiatry 40, 743-755.

Mundy P, Crowson M (1997). Joint attention and early social communication: implication for research on intervention with autism. Journal of Autism and Developmental Disorders 27, 653-676.

Nadel J (2002). Imitation and imitation recognition: functional use in preverbal infants and nonverbal children with autism. The Imitative Mind: Development, Evolution, and Brain Bases. In The Imitative Mind (ed. A. Meltzoff and W. Prinz), pp. 42-62. Cambridge University Press: Cambridge.

Nadel J, Aouka N, Coulon N, Gras-Vincendon A, Canet P, Fagard J, Bursztejn C (2011). Yes they can! An approach to observational learning in low-functioning children with autism. Autism 15, 421-435.

Nadel J, Butterworth G (1998). Imitation in Infancy. Cambridge University Press: Cambridge.

Neuhaus E, Beauchaine TP, Bernier R (2010).

Neurobiological correlates of social functioning in autism. Clinical Psychology Review 30, 733-748.

Nobile M, Alberti B, Zuddas A (2007). Conners' Rating Scales-Revised 2007 [Italian adaptation]. Giunti O.S. Organizzazioni Speciali: Florence.

O'Riordan MA, Plaisted KC, Driver J, Baron-Cohen S (2001). Superior visual search in autism. Journal of Experimental Psychology: Human Perception and Performance 27, 719-730.

Ozonoff S, Strayer DL (2001). Further evidence of intact working memory in autism. Journal of Autism and Developmental Disorders 31, 257-263. 
Pellicano E (2012). The development of executive function in autism. Autism Research and Treatment 2012, 146132-146140.

Petrosini L (2007). 'Do what I do' and 'do how I do': different components of imitative learning are mediated by different neural structures. Neuroscientist 13, 335-348.

Ramachandran V, Oberman L (2006). Broken mirrors: a theory of autism. Scientific American 295, 62-69.

Rizzolatti G, Craighero L (2004). The mirror-neuron system. Annual Review of Neuroscience 27, 169-192.

Robinson S, Goddard L, Dritschel B, Wisley M, Howlin P (2009). Executive functions in children with autism spectrum disorders. Brain and Cognition 71, 362-368.

Rogers SJ, Pennington BF (1991). A theoretical approach to the deficits in infantile autism. Development and Psychopathology 3, 137-162.

Rojas DC, Peterson E, Winterrowd E, Reite ML, Rogers SJ, Tregellas JR (2006). Regional gray matter volumetric changes in autism associated with social and repetitive behavior symptoms. BMC Psychiatry 6, 56.

Russell J (1997). Autism as an Executive Disorder. Oxford University Press: New York.

Rutter M (1974). The development of infantile autism. Psychological Medicine 4, 147-163.

Sears LL, Vest C, Mohamed S, Bailey J, Ranson BJ, Piven J (1999). An MRI study of the basal ganglia in autism. Progress in Neuro-psychopharmacology and Biological Psychiatry 23, 613-624.

Seidler RD, Purushotham A, Kim SG, Ugurbil K, Willingham D, Ashe J (2005). Neural correlates of encoding and expression in implicit sequence learning. Experimental Brain Research 165, 114-124.

Shah A, Frith U (1993). Why do autistic individuals show superior performance on the block design task? Journal of Child Psychology and Psychiatry 34, 1351-1364.

Shic F, Bradshaw J, Klin A, Scassellati B, Chawarska K (2011). Limited activity monitoring in toddlers with autism spectrum disorder. Brain Research 1380, 246-254.

Shih P, Shen M, Ottl B, Keehn B, Gaffrey M, Müller R (2010). Atypical network connectivity for imitation in autism spectrum disorder. Neuropsychologia 48, 2931-2939.

Silk TJ, Rinehart N, Bradshaw JL, Tonge B, Egan G, O'Boyle MW, Cunnington R (2006). Visuospatial processing and the function of prefrontal-parietal networks in autism spectrum disorders: a functional MRI study. American Journal of Psychiatry 163, 1440-14443.

Soulières I, Zeffiro TA, Girard ML, Mottron L (2011). Enhanced mental image mapping in autism. Neuropsychologia 49, 848-857.

Southgate V, Hamilton AF (2008). Unbroken mirrors: challenging a theory of autism. Trends in Cognitive Sciences 12, 225-229.

Spengler S, von Cramon DY, Brass M (2010). Resisting motor mimicry: control of imitation involves processes central to social cognition in patients with frontal and temporo-parietal lesions. Social Neuroscience 5, 401-416.

Stuss DT, Knight RT (2002). Principles of Frontal Lobe Function. Oxford University Press: Oxford.

Swick D, Ashley V, Turken U (2011). Are the neural correlates of stopping and not going identical? Quantitative meta-analysis of two response inhibition tasks. NeuroImage 56, 1655-1665.

Taylor BA, DeQuinzio JA (2012). Observational learning and children with autism. Behavior Modification 36, 341-360.

Théoret H, Halligan E, Kobayashi M, Fregni F, Tager-Flusberg H, Pascual-Leone A (2005). Impaired motor facilitation during action observation in individuals with autism spectrum disorder. Current Biology 15, R84-R85.

Torriero S, Oliveri M, Koch G, Lo Gerfo E, Salerno S, Ferlazzo F, Caltagirone C, Petrosini L (2011). Changes in cerebello-motor connectivity during procedural learning by actual execution and observation. Journal of Cognitive Neuroscience 23, 338-348.

Tsai PT, Hull C, Chu Y, Greene-Colozzi E, Sadowski AR, Leech JM, Steinberg J, Crawley JN, Regehr WG, Sahin M (2012). Autistic-like behaviour and cerebellar dysfunction in Purkinje cell Tsc1 mutant mice. Nature 488, 647-651.

Verhoeven JS, De Cock P, Lagae L, Sunaert S (2010). Neuroimaging of autism. Neuroradiology 52, 3-14.

Wechsler D (1991). Manual for the Wechsler Intelligence Scale for Children-3rd Edition. The Psychological Corporation: San Antonio, TX.

Williams JH, Whiten A, Singh T (2004). A systematic review of action imitation in autistic spectrum disorder. Journal of Autism and Developmental Disorders 34, 285-299.

Williams JH, Whiten A, Suddendorf T, Perrett DI (2001). Imitation, mirror neurons and autism. Neuroscience and Biobehavioural Reviews 25, 287-295. 